ISO 9001:2008 Certified

International Journal of Engineering and Innovative Technology (IJEIT)

Volume 11, Issue 1, July 2021

\title{
Design and Simulation of Automatic Street Lighting System using Solar
}

\author{
Kavitha Chenna Reddy, Kulshrestha Utkarsh Alok, Chandrashekar C, Md. Farhanulla Sharif
}

\begin{abstract}
The project is designed for Solar powered pedestal street lights that uses solar power from PV cells. For controlling the charging of the battery a charge controller is been used, and an LDR is used to sense the light on day as well as the evening time. The intensity of street lights is required to be kept high during the peak hours. The street lights are switched on using a sensing device LDR LED lights at the dusk and then switched off automatically when the timer set in the timer relay module stops. Due to which there is low energy consumption and the system works long life so that they can fast replace conventional lights world over. White light emitting diode (LED) replaces the HID lamps due to which the light gets saved and the system works without any problem. For energy saving of solar based system, also a charge controller is used to protect the battery from over charging, overloading and deep dischargeing protection. A light sensing device LDR (Light Dependent Resistance) is used, whose resistance reduces drastically for sensing purposes. In the measuring circuit the light intensity is monitored using an Light Dependent Resistance sensor and an signal from ldr sensor is send to the relay timer module and the times gets started and, after the time finishes the relay attached to the relay timer module gets open and the street lights stops. The design for this proposed project is modeled in PROTEUS 8 and acceptable results came at the end.
\end{abstract}

Index Terms - Charge Controller, Solar Panel, Street Light, and Relay Timer Module.

\section{INTRODUCTION}

The main conscious in the present technologies is automation, power Consumption and cost-effectiveness. Giving street lighting is one of the most important responsibilities of a city management [4]. Energy efficient technologies can reduce cost of the pedestal street lighting intensely [1]-[9]. There are numerous number of control strategy and methods in controlling the street light system to confirm that it consumes low energy and is effective in terms of money and usage [3]-[9]. The energy consumption in entire world is increasing at the very fastest rates due to population growth and economic-development and the availability of energy sources remains bitterly unnatural [3]. Resource scar city and growth in energy demand and supply therefore, India continues to face serious energy scarcity [1]-[9].The major indicators of India's energy problems include; Over $40 \%$ of the households (particularly rural areas) indo not have electricity, about a third of our total primary-energy supply to rural areas still comes from non-conventional sources [3] (eg.biomass, dung) and currently India is facing wide demand supply gap of about 15-25 per cent energy-shortage [3].

Manuscript received: 25 June 2021

Manuscript received in revised form: 20 July 2021

Manuscript accepted: 6 August 2021

Manuscript Available online: 15 August 2021
Due to scarcity of the energy supply till present several rural areas have not ease with electricity and even if provided, the supply of the electricity is very limited to few hours a day and are facing unusual problems due to infinite number of power cuts [5]-[7].

The current project focuses at solving one of the major issues in the village areas which faces seriousuncontro lled power cut problems [6]. During the day time, we get lot of amount of light energy from solar and the problem for pedestals is similar during the night time [4]. Though lots of the streets are equipped with street lights every rural areas but because of uncontrolled power failures/power-cut it become a serious problem for rural people to commute for irrigational field work during the night time due to limit-less power cuts [2].

The project's main aim is to harvest the energy from non-conventional energy source like sun and to properly use the harvested energy for the benefit of remote villages (Rural people) facing serious power problems. The main objective of the project is to provide a "Solar powered pedestal lighting system" powered with solar energy to assist the rurals during the night time [3]-[5].

By combining the whole street lights with the system it is possible to properly help the pedestrian-to reach the desired destination in the village which are facing serious electric power supply problem [2] [4]. The same system can also be used for the home light [3].

\section{OBJECTIVE}

The important objective of this paper is to give a better solution to minimize the electricity wastages in operating street lights, in this era humans are restless [1]-[5]. Manual control is susceptible to errors and leads to electricity wastage. This paper presents an automatic street light controller with the help of light dependent resistor (LDR) [3]-[5] and relay timer module. LDR is which also known as photo resistor is made cadmium sulfide [3]. The circuit also consists of a charging controller [3]-[5]. The light intensity is inspected using an LDR sensor. The objective is to compensate the growing energy demand by with the help of renewable energy source i.e. solar [9]. With the help of this project, lights the streets of rural area [3]. The consumption of power will be low. The principal objective is to reduce power loss. One more objective is to increase the durability and longevity [7]. The requirement of Maintenance will be low in our system. 
ISSN: 2277-3754

ISO 9001:2008 Certified

International Journal of Engineering and Innovative Technology (IJEIT)

Volume 11, Issue 1, July 2021

\section{METHODOLOGY}

The energy produced by the solar panel is used to charge Lithium-Ion Battery as depicted with the help of Fig.1. The load is powered using the energy stored in the Lithium-Ion battery through charge controller [1]. The charge controller is used to control the overcharging and deep dischargeing of the battery, which increases the life of the battery [1]. After the energy stored in the battery with the help of relay timer module the LED starts to glow simultaneously the timer in the relay timer module starts as seen in Fig.1 [8]. Relay timer module is the module which consists of a timer and a relay. When the signal through the LDR [3] sends to the relay timer module the timer starts and the LED Street light also starts to glow and when the timer starts the LED street light stops.

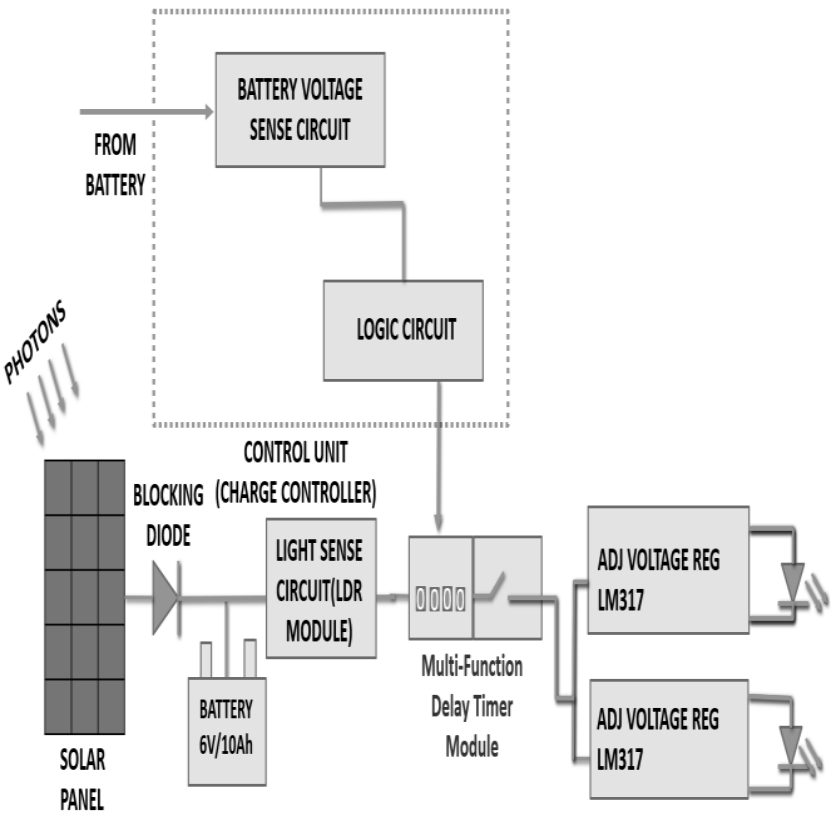

Fig.1. Block Diagram of proposed system

\section{WORKING}

The working of the Solar Powered Pedestal Street Light is as follows: In the Proposed System from Fig.1,The sunlight falls on the Solar Panel and the energy from the Solar Panel gets stored in the battery. In the system there is also a charge controller attached so we can get the information of how much energy in the form of electricity is stored in the battery. Also, to control the overcharging of the battery so that the system does not gets spoiled. The charge controller is connected to solar panel, rechargeable battery and the LED Street light. At the evening time when the sun goes down, the LDR with the help of light intensity detects [1]-[4] and send the signal to the relay timer module. Relay timer module is a timer module which is interface with the relay. Hence the timer start its count when the signal is detected and at the same time the relay also gets to the $\mathrm{NC}$ (Normally Closed) position from NO (Normally Open) position and the LEDs in the street light start. After certain duration of time set in the relay timer module the timer gets stop and the relay from $\mathrm{NC}$ position comes back to NO position and hence the light stops. Again, on the next day solar panel starts to store the sunlight and the process start again.

\section{CIRCUIT DESCRIPTION}

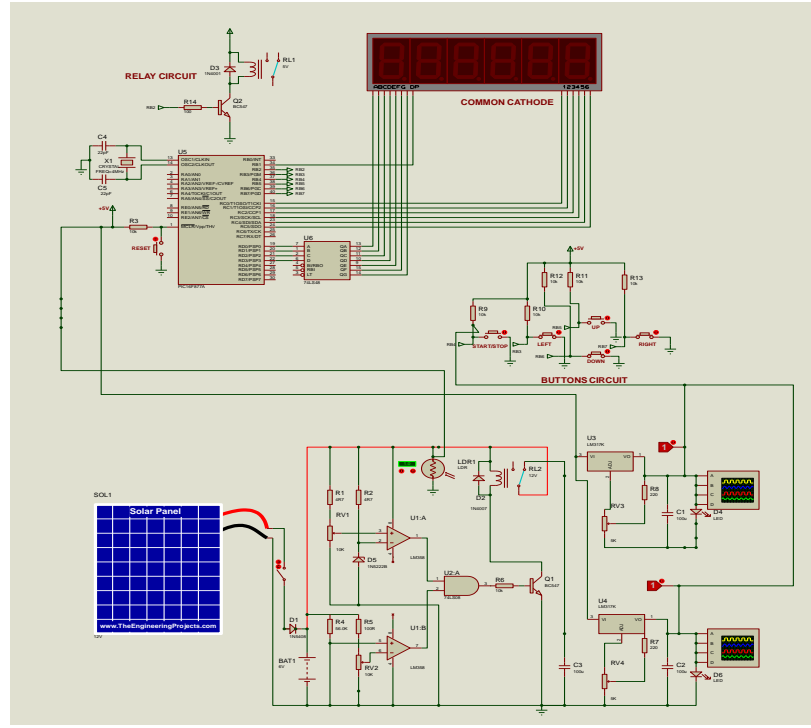

Fig.2.Circuit Diagram

The components used are as follows:

1. Charge Controller

2. LDR

3. LED Lights

4. Rechargeable Battery

5. Relay Timer Module

6. Resistors

7. Solar Panel

The Solar Panel is connected to the charge controller and a rechargeable battery and it is also connected to diode D1 depicted in Fig.2. Here the battery used is of 9V. That battery is been connected to the solar panel and the charge controller also the battery is connected to LM358 U1:A and U1:B as shown in Fig. 2. Then from the charge controller and battery it is connected to LDR, LDR is used to detect the intensity of light when the sun goes down due to less intensity the signal is hence send to the relay timer module which is connected to the LDR.

The charge controller consists of two circuit from Fig.2

1.) Battery Voltage Sense Circuit.

2.) Logic Circuit.

These two circuits combine to form charge controller which inspects that how much energy is stored in the battery and it also saves the battery from overcharging and getting damaged. For logic circuit we are using AND gate U2: A shown in Fig.2. And for battery voltage sense circuit we are considering LM358 U1:A and U1:B shown in Fig.2. From relay timer module voltage regulator LM317K U3 and U 4 are connected and then U3 and U4 are connected to LED's D4 and D6 respectively. When the sun goes down, the LDR detects that the intensity of light is less so LDR sends a signal to the relay timer module. The timer set in that module gets started and the relay gets open. And so, the charge stored in 
ISSN: 2277-3754

\section{ISO 9001:2008 Certified}

International Journal of Engineering and Innovative Technology (IJEIT)

Volume 11, Issue 1, July 2021

the battery releases and goes directly to the LED lights and hence the street light is switched ON due to direct charge from the battery.

In the relay timer module, we can give the time for which the relay should be ON i.e., in the NC (Normally Closed) contact. When the time in the relay timer module gets over the relay automatically comes from NC (Normally Closed) contact position to NO (Normally Open) contact position. And thus, the relay gets open and the flowing of current into the street lights stops and the charging in the battery with the help of solar panel starts.

\section{SIMULATION}

The designing and simulation of our project is done in the software named as PROTEUS 8. It was introduced in Yorkshire, England by Lab center Electronics Ltd. It is a simulation and design tool created by Lab center. It also has $2 \mathrm{D}$ and $3 \mathrm{D}$ CAD drawing feature. It is also used for the analyze of the designed circuit. The Simulation of our project consists of three stages:

1.) When the relay timer module starts.

2.) When the relay timer is ongoing.

3.) When the timer has stopped.

\section{1.) When the relay timer module starts-}

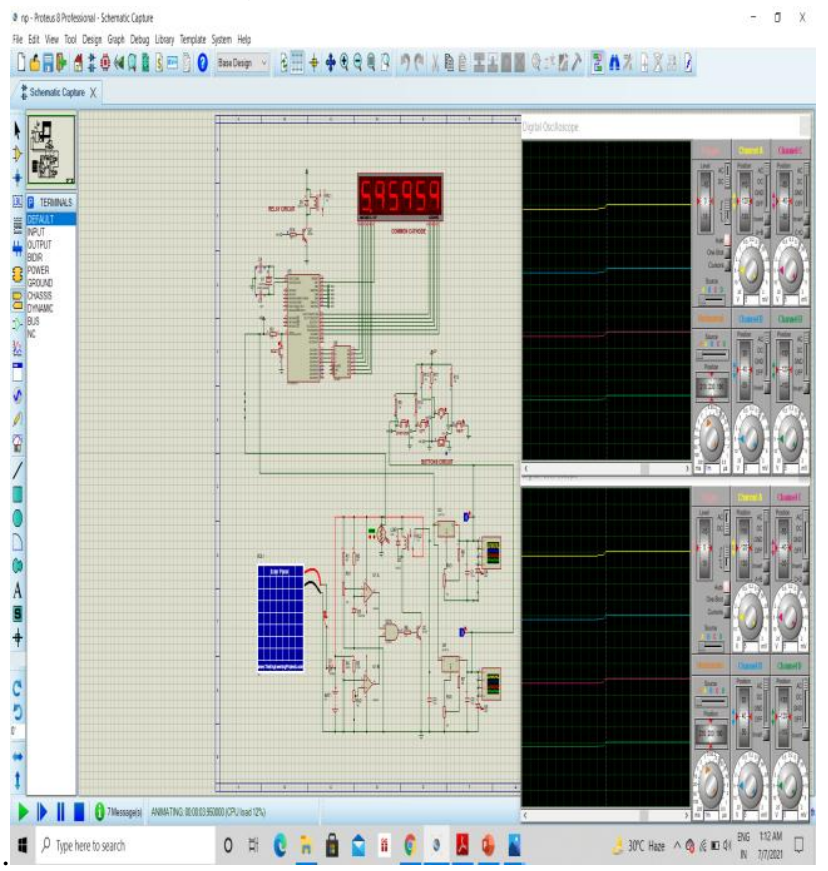

Fig.3. When the relay timer module starts

When the relay timer module starts by pressing the push button here push button indicates that the signal is send from the LDR when the sun goes down to the relay timer module. The output at that instance is depicted with the help of the oscilloscope in Fig. 3 attached to the LED Street light. The output here is shown when the sun goes down and the LDR sends signal to the relay timer module and hence the LED street lights starts glowing. Here the glowing of LED is shown by the rising of the graph in Fig. 3 .

\section{2.) When the relay timer is ongoing.}

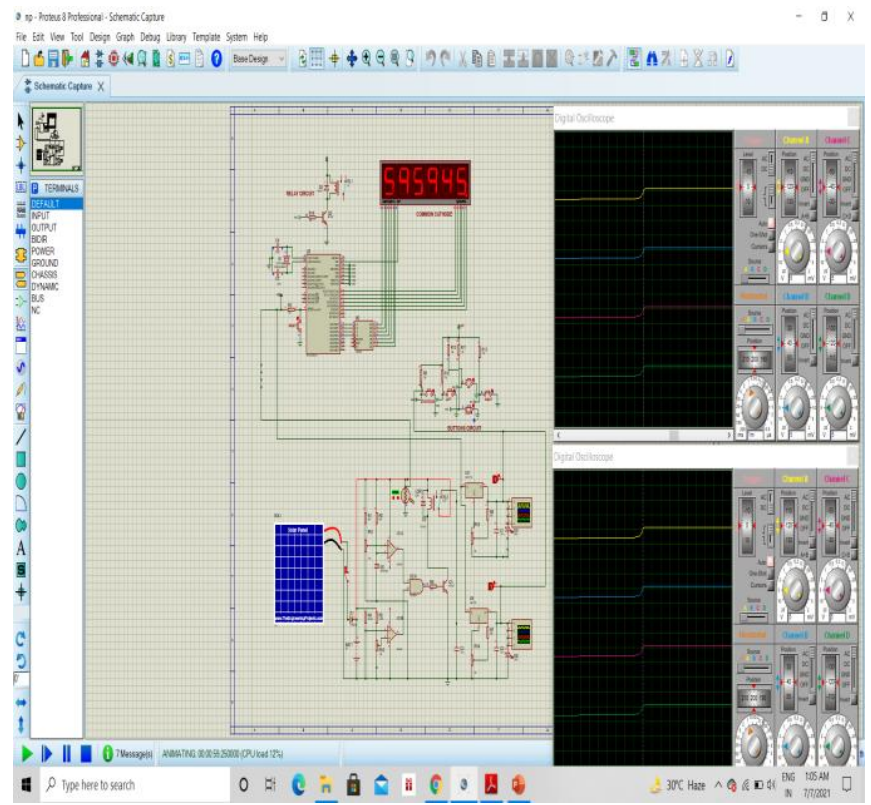

Fig.4. When the relay timer is ongoing.

When the relay timer is in ongoing process. When the Timer is in ON position i.e., ongoing the deviation is properly seen via oscilloscope screen Which indicates that the LED Street light is still ON shown in Fig.4.

\section{3.) When the timer has stopped.}

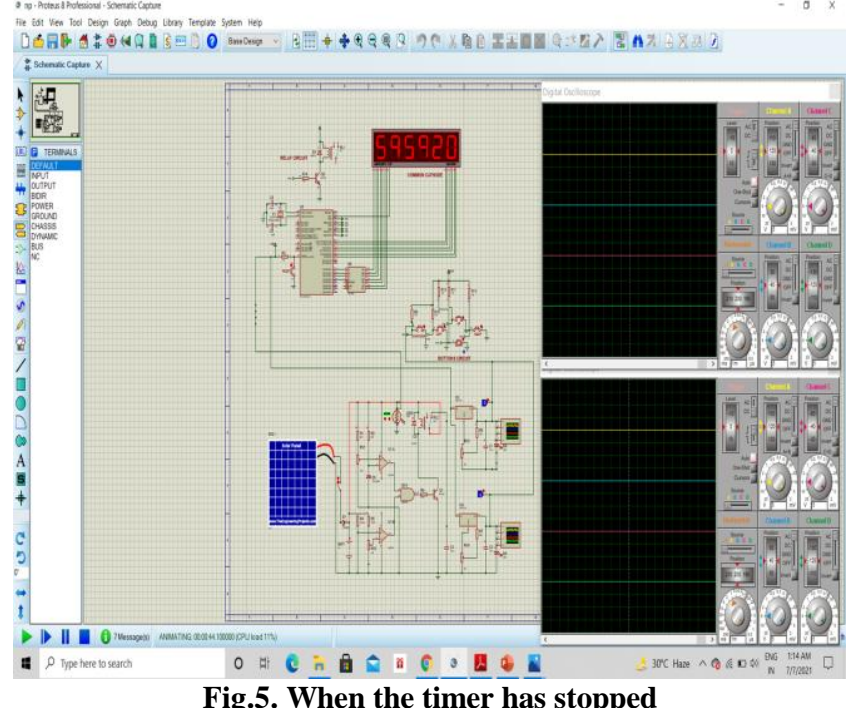

When the time set in the timer gets over. When the time gets over the relay opens and the LED street light stops which is shows via straight line in the oscilloscope.

\section{RESULTS}

In this paper, 'SOLAR POWERED PEDESTAL

LIGHTING SYSTEM' is developed. Here the same results have been provided in two states i.e., 1.) When the relay timer module starts and 2.) When the relay timer is ongoing. Which shows that the LEDs are in ON position and in third state.3.) When the timer has stopped the graph shows the straight 
ISSN: 2277-3754

ISO 9001:2008 Certified

International Journal of Engineering and Innovative Technology (IJEIT)

Volume 11, Issue 1, July 2021

which means the LEDs are in OFF position. So, here we get the result with successful simulation.

\section{CONCLUSION}

The main motive of this project is to design, perform and develop a system for saving energy of streetlights with light depending resistor and relay timer module. At present, humans have become too busy and are unable to have time even to switch OFF lights whenever not necessary. These are seen more often in the case of street lights. In the present system, the streetlights will be switched $\mathrm{ON}$ in the evening before sun set and they are switched OFF the next day when there is sufficient light on the roads. But the lights need to be switched on when there is absolute darkness. Due to this there is some power loss. This project is the best solution for such electrical power wastage and there is no need of manual operation.

\section{FUTURE SCOPE}

The aim of the project was to make it attainable within the allotted period of time. Many improvements can be made using this starting design. As this design shows a mini model it can be executed to a much larger scale. The ideas for future expansion of this project are as follows:

The sensitivity of the tracking system can be improved by using different kinds of light sensors. A photodetector with amplifying circuit can be used for such cases.

Different sorts of algorithm can be used for more improved tracking. We can add more intelligence to the device, like after tracing the solar light it can predict the movement of the sun across the sky by its own.

In monsoon season it is very burdensome to get solar light so batteries can be connected in series to save power.

A digital display can also be attached which shows the energy stored in battery and the intensity of light at the same time.

\section{ACKNOWLEDGMENT}

The satisfaction and euphoria that accompany the successful completion of any task would be incomplete with-out the mentioning of the people whose constant guidance and encouragement made it possible. We take pleasure in presenting before you, our project, which is result of studied blend of both research and knowledge. We express our earnest gratitude to the management New Horizon College of Engineering, for their constant support, encouragement and guidance.

\section{REFERENCES}

[1] Suhil Kiwan, Anwar Abo Mosali, Adnan Al-Ghasem, "Smart Solar-Powered LED Outdoor Lighting System Based on the Energy Storage Level in Batteries", Buildings MDPI Journal, Volume 8, Issue 9, August 2018, pp: 1-18.

[2] Pranav Rao, S R Dhanush, Ajesh ,Rajesh Nayak, "Solar Powered Smart Pedestal Lighting System An innovation to light up the rural India smartly", A TRIP project sanctioned by
Vision Group on Science and Technology(VGST) -Govt. of Karnataka,2019,pp:1-24.

[3] Ch Kavitha, Swathi, Satyaprakash, Vinitha, "Solar Powered LED Street Lighting with Auto Intensity Control", International Journal of Scientific \& Engineering Research, Volume 7, Issue 7, July-2016,pp:34-37.

[4] Fares S. El-Faouri, Munther Sharaiha, Daoud Bargouth, and Ayman Faza, "A Smart Street Lighting System Using Solar Energy", IEEE International Conference, October 2016,pp:1-6.

[5] B. G. Shivaleelavathi; Vinay M E; Sucheeth V, "Solar Based Smart Street Lighting System", International Conference on Electrical, Electronics, Communication, Computer, and Optimization Techniques (ICEECCOT), Mysore, India, 14-15 Dec. 2018,pp:1479-1483.

[6] M.Deepu Vijay, Kamlesh Shah, G.Bhuvaneswari, Bhim Singh, "LED based street lighting with automatic intensity control using solar PV", IEEE IAS Joint Industrial and Commercial Power Systems / Petroleum and Chemical Industry Conference (ICPSPCIC), Hyderabad, India, 19-21 Nov. 2015,pp:197-202.

[7] Richu Sam Alex, R Narciss Starbell, "Energy Efficient Intelligent Street Lighting System Using ZIGBEE and Sensors", International Journal of Engineering and Advanced Technology, Volume-3, Issue-4, April 2014,pp:41-44.

[8] Mokhtar Ali, Mohamed Orabi, Emad Abdelkarim , Jaber A. Abu Qahouq and Abdelali El Aroudi, "Design and Development of Energy-Free Solar Street LED Light System", IEEE PES Conference on Innovative Smart Grid Technologies - Middle East (ISGT Middle East),December 2011,pp:1-7.

[9] Gouthami. C, Santosh. C, A. Pavan Kumar, Karthik. A, Ramya.K.R" Design and Implementation of Automatic Street Light Control System using Light Dependent Resistor", International Journal of Engineering Trends and Technology (IJETT), V35 (10), May 2016, pp: 465-470.

\section{AUTHOR'S PROFILE}

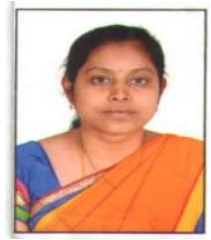

Professor Kavitha Chenna Reddy is an M.Tech Scholar of High Voltage Engineering at JNTU University Kakinada, Andhra Pradesh, India. She has earned her Bachelor's Degree (B.Tech) in EEE in 2004 from Baptala College of Engineering. She is presently working as Asst. professor in the Department of Electrical and Electronics Engineering at New Horizon College of Engineering, Bangalore, Karnataka, India. She has presented eight papers in International conferences in the field of include High Voltage, Ac-Dc Converters, Synchronous Machines, Voltage Distribution, Renewable Energy, Power System Protection. Ms. Kavitha Chenna Reddy is a member of INTERNATIONAL ASSOCIATION OF ENG. Her research interests include High Voltage, Ac-Dc Converters, Synchronous Machines, Voltage Distribution, Renewable Energy, and Power System Protection.

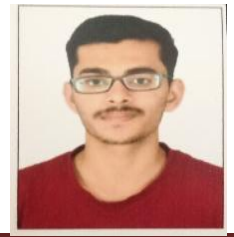

Kulshrestha Utkarsh Alok is an undergoing B.E student currently in $3^{\text {rd }}$ year of Electrical and Electronics Engineering (EEE) at New Horizon 
ISSN: 2277-3754

ISO 9001:2008 Certified

International Journal of Engineering and Innovative Technology (IJEIT)

Volume 11, Issue 1, July 2021

College of Engineering, Bangalore, India. He has completed his $12^{\text {th }}$ in 2018

from Narayana IIT Academy Hyderabad, Telangana, India He has presented one paper in an International conference in the field of Li-Fi technology. And he has also filed a patent through $\mathrm{R} \& \mathrm{D}$ of New Horizon College of Engineering, Bangalore, India in the field of Renewable Energy (Solar). Kulshrestha Utkarsh Alok is a member of IEEE, Power Electronics Society (PELS). His research interests include Renewable Energy (Solar), Li-Fi Technology, RFID Technology, IoT.

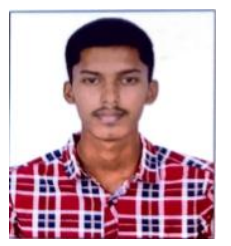

Chandrashekar $\mathbf{C}$ is an undergoing B.E. student currently in $3^{\text {rd }}$ year of Electrical and Electronics Engineering (EEE) at New Horizon College of Engineering, Bangalore, India. He has completed his $12^{\text {th }}$ in 2018 New Horizon Pre-University College, KasturiNagar, Bangalore, Karnataka, India. $\mathrm{He}$ has successfully implemented the mini-project given in New Horizon College of Engineering, Bangalore, and Karnataka by using LM324IC, Piezo buzzer, MQ6 sensor technology, CA 3130 IC, 7805 IC Technologies. His research interests include Sensors Technology, Power System Protection, IoT, voltage regulators, Solar Energy.

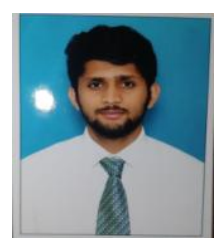

Md. Farhanulla Sharif is an undergoing B.E. student currently in $3^{\text {rd }}$ year of Electrical and Electronics Engineering (EEE) at New Horizon College of Engineering, Bangalore, India. He has completed his $12^{\text {th }}$ in 2017 New Horizon Pre-University College, Kasturi Nagar, Bangalore, Karnataka, India. He has successfully implemented the mini-project given in New Horizon College of Engineering, Bangalore, Karnataka in the field of Arduino and RFID Technology. His research interest includes RFID Technologies, Arduino, Motors, IoT. 